\title{
A TEST OF SECOND-ORDER STOCHASTIC DOMINANCE WITH DIFFERENT WEIGHTING METHODS: EVIDENCE FROM BIST-30 and DJIA
}

\section{DOI: 10.17261/Pressacademia.2015414538}

\author{
Oktay Tas', Farshad Mirzazadeh Barijough ${ }^{2}$, Umut Ugurlu ${ }^{3}$ \\ 'Istanbul Technical University, Turkey. Email: oktay.tas@itu.edu.tr \\ ${ }^{2}$ Istanbul Technical University, Turkey. Email: mirzazadeh@itu.edu.tr \\ ${ }^{3}$ Istanbul Technical University, Turkey. Email: ugurluum@itu.edu.tr
}

\section{Keywords \\ Portfolio Selection, Second-Order stochastic dominance, Mean-Variance, BIST, NYSE, Different Weighting}

JEL Classification G11,G14

\begin{abstract}
Portfolio optimization is one of the most important steps in asset allocation procedure. Having optimized portfolios with Markowitz Mean-Variance, recently Stochastic Dominance method is taking place as a preliminary test in efficient asset allocation procedure. In some studies, it is even used as an alternative method to replace meanvariance theory in portfolio selection. In this research, distributionbased Stochastic Dominance method applied to discover the dominant individual stocks of DJIA and BIST-30 indices. We conducted Secondorder Stochastic Dominance (SSD) method with various weighting logic Equal, Simple and Logarithmic. This paper concerns about two concepts; firstly, investigating market efficiency with SSD in one emerging and one developed market, Borsa Istanbul and New York Stock Exchange, respectively. Secondly, the impact of different weighting methods in dominant portfolios. Results illustrate that, there are differences in dominant portfolios with various weighting methods. Further, NYSE seems more efficient market than BIST.
\end{abstract}

\section{INTRODUCTION}

All investors concerned about how to select optimal portfolio that fulfill the investment objectives over the investment horizon. The importance of decision making based on expected return of financial assets is one of the most controversial topics in investment. In this respect, decision theory can be seen as the field that describes and formalizes the process of making a choice among several possible uncertain alternatives (Castellano \& Cerqueti, 2013). Basically there are two asset allocation approaches; heuristic and quantitative. In the former method the investor selects portfolio based on his or her feelings and expectations, but in the latter method assets are being allocated using mathematical optimization methods.

As a quantitative method, Markowitz (1952) proposed his genesis model of return and risk in portfolio selection, which initiated the Modern Portfolio Theory. Because of its 
simplicity, this model is commonly used in asset allocation and practical funding decisions. He concluded that, asset's performance should be measured in two specific dimensions: the mean describing the expected return, and the variance which measures the uncertainty and volatility of the return. However, he also suggested other measures of risk e.g. semi-variance (Markowitz, 1959). Although, describing the risk of an asset in term of variance is due to its straightforward computation, the variance is not a satisfactory measure of risk. Firstly, due to its symmetric behavior, i.e. variance penalizes gains and losses equally. Secondly, variance cannot describe the risk of low probability events such as, default risk. (Copeland, Weston, \& Shastri, 1998). In the Markowitz mean-variance approach, efficient portfolios are selected from the universe of all possible portfolios; then for a given value of the return the risk will be minimized or, analogously, for a given level of risk, the mean will be maximized. With this method the portfolio selection procedure could be formulated as a parametric optimization problem, which assists the trade-off between risk and return. (Markowitz, 1952).

On the other hand, Stochastic Dominance method is taking place as a preliminary test in efficient asset allocation procedure. In some papers, it is even used as an alternative method to replace mean-variance theory in portfolio selection (Guran \& Tas, 2013). Firstorder and Second-order stochastic dominance was introduced independently by Hadar and Russell (1969), Hanoch and Levy (1969), Hadar and Russell (1969), and also the Thirdorder stochastic dominance suggested by Whitmore (1970). The concept of stochastic dominance is related to models of risk-averse preferences (Sisson, 1965). It initiated from the theory of majorization for the discrete case (Marshall, Olkin, \& Arnold, 2011) and later extended to general distributions, and is now vastly applied in economics and finance (Hanoch \& Levy, 1969). According to Kroll and Levy (1980), Levy (1992), stochastic dominance is a central concept in a wide variety of applications in economics, finance and statistics. An important reason of this, is it does not need two or more portfolios to compare. It is possible to evaluate just a portfolio by second order stochastic dominance. Stochastic dominance tries to compare random variables in the sense of stochastic order expressing the common preferences of rational decision-makers. It is an alternative theoretical approach to the mean-variance portfolio selection problem.

This study applies distribution-based second-order stochastic dominance, which proposed by Dentcheva and Ruszczyski (2003), Dentcheva and Ruszczysk (2006) and Kopa and Chovanec (2008). We proceed analogously to Tas and Guran (2015) on Borsa Istanbul (BIST-30) and Dow Jones Industrial Average (DJIA) to discover the dominant portfolios of these indices. We conduct this method with various weighting techniques. This work investigates market efficiency with SSD in one emerging and one developed market, then it looks after the impact of different weighting methods in dominant portfolios.

\section{LITERATURE REVIEW}

Many studies have been done to measure performance of portfolios based on secondorder stochastic dominance. Best et al. (2000) states value portfolios second order stochastically dominate growth portfolios. Fong (2009) concludes that in Chinese stock market A-shares second-order stochastically dominate B-shares. It means that all risk 
averse investors will prefer A-Shares to B-Shares. Tas and Ugurlu (2015) examined Turkish mutual funds based on Second-order Stochastic Dominance and compared with conventional portfolio performance measures. Isiker et al. (2014) compares 12 ethical and 12 conventional stocks from Borsa Istanbul with SSD efficiency test. According to the results, ethical stocks seems more efficient than conventional ones.

Guran et al. (2013) observes the efficiency of BIST-30 Index portfolio by second order stochastic dominance. Data is used from 03.12.2010 to 05.07.2013 on weekly basis. All 30 stocks are second order stochastically pairwise compared. Only 12 of 30 stock are not second orderly dominated and can be used in an efficient portfolio of BIST-30. Total weight of these 12 stocks are $34.64 \%$. In accordance with these results, BIST-30 is not an SSD efficient index. The underlying desire behind this study was to have a look on SSD portfolios with various weighting tactics.

\section{DATA AND METHODOLOGY}

The First-order stochastic dominance - which is rare in financial instruments - is defined as

$$
F_{i}(t) \leq F_{j}(t) \forall_{t} \text { For all } t
$$

reveals that asset $i$ stochastically dominants asset $j$ in first order. In other words asset $i$ is preferable on asset $j$. FSD does not require any restriction on investors' utility function. Further Second-order noted as

$$
\int_{-\infty}^{X} F_{i}(t) d t \leq \int_{-\infty}^{X} F_{j}(t) d t
$$

considers that investors are risk-averse. The definition of second-order stochastic dominance relation uses comparisons of either twice cumulative distribution functions, or expected utilities (Levy, 1998). Alternatively, one can define SSD relation using cumulative quantile functions or conditional value at risk (Ogryczak \& Ruszczyn, 2002). Daily returns of BIST-30 and DJIA from 1 Jan 2012 until 1 Jan 2014 were studied, it worth to mention; due to lack of historical prices, Pegasus Airlines eliminated from BIST-30 and it considered with 29 stocks.

$$
r_{t}=\frac{P_{t+1}}{P_{t}}-1
$$

Then the stochastic dominance process were applied on both indices. The key different point from the Tas et al. (2014) work is that, in finding dominant assets we applied three weighting tactics. First one is Equal-weighted, which assigns the same significance to all returns within time horizon. Second tactic is Simple-Weighted, which assign the significance to return based on time of occurrence. The last one is somehow same to the simple-weighted, however the significance assigned regarding to Logarithmic-Weighted. 
Equal-Weighted: $w_{i}=\frac{1}{t}, t$ stands for time horizon.

Simple-Weighted: $w_{i}=\frac{z}{\sum_{i=1}^{t} z_{i}}, z$ stands for order of occurrence

Logarithmic-Weighted: $w_{i}=\frac{\log (z)}{\sum_{i=1}^{t} \log \left(z_{i}\right)}, z$ stands for order of occurrence

By applying this procedure for both of indices, the output is four cluster of stocks for each index:

- Cluster 1. The stocks which dominate at least one stock and are not dominated by any other.

- Cluster 2. The stocks which are dominated by at least one stock and do not dominate any other stock.

- Cluster 3. The stocks which are dominated by at least one stock and dominate at least one other stock.

- Cluster 4. The stocks which are not dominated by any stock and do not dominate any other stock.

Obviously, stock which taking place in $1^{\text {st }}$ cluster are the dominant stocks. In the previous studies Tas et al. (2014) and Tas and Guran (2015) took all assets in $1^{\text {st }}$ and $4^{\text {th }}$ clusters to make dominant portfolios, however, in this study for purpose of back-testing only stock in $1^{\text {st }}$ were taken to construct portfolio. Daily returns 1 Jan -1 Apr 2014 were used to make equally weighted portfolios with individual stocks in Cluster 1 and also mutual stocks between three weighting tactics for each indices. The return of these portfolios are compared via excess return from index's return.

\section{RESULTS}

Table 1 shows the components of Borsa Istanbul 30 Index (BIST-30). Pegasus Airlines, which does not have full data in the examination period is excluded. 
Table 1. BIST-30 Components

\begin{tabular}{|lll|}
\hline \multicolumn{3}{c|}{ SYmbol Reference } \\
\hline 1. AKBANK & 11. TURKIYE IS BANKASI 'C' & 21. TURK HAVA YOLLARI \\
2. ARCELIK & 12. KOC HOLDING & 22. TEKFEN HOLDING \\
3. BIM BIRLESIK MAGAZALAR & 13. KOZA ALTIN ISLETMELERI & 23. TOFAS TURK OTOM.FABK. \\
4. DOGAN SRKGRBU.HLDG. & 14. KARDEMIR 'D' & 24. TRAKYA CAM SANAYI \\
5. EMLAK KONUT & 15. MIGROS TICARET & 25. TURK TELEKOMUNIKASYON \\
GAYRIMENKUL YATOTA. & 16. PETKIM PETROKIMYA & 26. TUPRAS TKI.PEL.RFNE. \\
6. ENKA INSAAT VE SANAYI & HLDG. & 27. ULKER BISKUVI SANAYI \\
7. EREGLI DEMIR CELIK & 17. HACI OMER SABANCI HLDG. & 28. VAKIF FINANSAL KIRALAMA \\
8. FORD OTOMOTIV SANAYI & 18. TKI.SISE VE CAM FKI. & 29. YAPI VE KREDI BANKASI \\
9. TKI.GARANTI BKSI. & 19. TAV HAVALIMANLARI & 29. \\
10. TURKIYE HALK BANKASI & 20. TURKCELL ILETISIM HZM. & \\
\hline
\end{tabular}

Tables 2 and 5 illustrate the clustering stocks' results of BIST-30 and DJIA respectively. Obviously, the $4^{\text {th }}$ cluster of DIIA does not contain any stocks, which means that all components are whether dominant or dominated-by. However, stock No.27 in BIST-30 does not dominate any stock and it is not dominated by any individual component.

Table 2. Second Order Stochastic Dominant and Dominated Stocks

\begin{tabular}{|c|c|c|c|c|c|c|c|c|c|c|c|c|c|}
\hline \multicolumn{5}{|c|}{ Equally Weighted } & \multirow[b]{2}{*}{19} & \multirow[b]{2}{*}{20} & \multirow[b]{2}{*}{21} & \multirow[b]{3}{*}{23} & \multirow[b]{3}{*}{28} & \multirow[b]{4}{*}{25} & \multirow[b]{4}{*}{26} & \multirow[b]{4}{*}{29} & \\
\hline Cluster 1. & 2 & 3 & 12 & 16 & & & & & & & & & \\
\hline Cluster 2. & 4 & 8 & 9 & 10 & 13 & 14 & 22 & & & & & & \\
\hline Cluster 3. & 1 & 5 & 6 & 7 & 11 & 15 & 17 & 18 & 24 & & & & \\
\hline Cluster 4. & 27 & & & & & & & & & & & & \\
\hline \multicolumn{5}{|c|}{ Simple Weighted } & & & & & & & & & \\
\hline Cluster 1. & 7 & 12 & 16 & 19 & 20 & 21 & 24 & & & & & & \\
\hline Cluster 2. & 4 & 8 & 9 & 10 & 13 & 22 & 23 & 28 & & & & & \\
\hline Cluster 3. & 1 & 2 & 3 & 5 & 6 & 11 & 15 & 17 & 18 & 25 & 26 & 27 & 29 \\
\hline Cluster 4. & 14 & & & & & & & & & & & & \\
\hline \multicolumn{5}{|c|}{ Logarithmic Weighted } & & & & & & & & & \\
\hline Cluster 1. & 1 & 13 & 16 & 23 & 24 & 28 & 30 & & & & & & \\
\hline Cluster 2. & 4 & 8 & 9 & 10 & 13 & 14 & 22 & 23 & 28 & & & & \\
\hline Cluster 3. & 1 & 5 & 6 & 11 & 15 & 17 & 18 & 24 & 25 & 26 & 29 & & \\
\hline Cluster 4. & 27 & & & & & & & & & & & & \\
\hline
\end{tabular}


Table 3 and 6 represent the constructed portfolios from dominant stocks. In both indices, Equally weighted SSD portfolios have the highest excess return. Since the Simple and Logarithmic weighted tactics assign priority on recent returns, Equally weighted portfolios rejected the idea of the higher excess returns with much recent information.

Table 3. Dominant Portfolios' and Excess Returns

\begin{tabular}{|lc|c|}
\hline Dominant Portfolio & Return & Excess Return \\
\hline Equally Weighted & $-5.28 \%$ & $0.73 \%$ \\
Simple Weighted & $-6.78 \%$ & $-0.77 \%$ \\
Logarithmic Weighted & $-5.40 \%$ & $0.61 \%$ \\
Mutual Assets & $-5.39 \%$ & $0.62 \%$ \\
\hline BIST 30 & $-6.01 \%$ & \multicolumn{1}{|c}{} \\
\cline { 1 - 2 } & &
\end{tabular}

In the bearish backtesting period, BIST-30 loses $6.01 \%$ and equally weighted, logarithmic weighted and mutual portfolios outperform the BIST-30 Index. On the other hand, performance of the simple weighted portfolio cannot exceed the performance of BIST-30 Index.

Table 4 gives the components of Dow Jones Industrial Average (DJIA).

Table 4. DJIA Components

\begin{tabular}{|lll|}
\hline \multicolumn{3}{|c|}{ Symbol Reference } \\
\hline 1. 3M & 11. GENERAL ELECTRIC & 21. NIKE 'B' \\
2. AMERICAN EXPRESS & 12. GOLDMAN SACHS GP. & 22. PFIZER \\
3. ATandT & 13. HOME DEPOT & 23. PROCTER and GAMBLE \\
4. BOEING & 14. INTEL & 24. TRAVELERS COS. \\
5. CATERPILLAR & 15. INTERNATIONAL BUS.MCHS. & 25. UNITEDHEALTH GROUP \\
6. CHEVRON & 16. JOHNSON and JOHNSON & 26. UNITED TECHNOLOGIES \\
7. CISCO SYSTEMS & 17. JP MORGAN CHASE and CO. & 27. VERIZON \\
8. COMMUNICATIONS \\
9. E I DU PONT DE & 18. MCDONALDS & 28. VISA 'A' \\
NEMOURS & 19. MERCK and COMPANY & 29. WAL MART STORES \\
10. EXXON MOBIL & 20. MICROSOFT & 30. WALT DISNEY \\
\hline
\end{tabular}


Table 5. Second Order Stochastic Dominant and Dominated Stocks

\section{Equally Weighted}

$\begin{array}{llllllll}\text { Cluster 1. } & 1 & 13 & 16 & 24 & 26 & 28 & 30\end{array}$

$\begin{array}{llllllll}\text { Cluster 2. } & 5 & 7 & 12 & 14 & 15 & 17 & 20\end{array}$

$\begin{array}{lllllllllllllllll}\text { Cluster 3. } & 2 & 3 & 4 & 6 & 8 & 9 & 10 & 11 & 18 & 19 & 21 & 22 & 23 & 25 & 27 & 29\end{array}$

Cluster 4.

\section{Simple Weighted}

$\begin{array}{lllllllllllll}\text { Cluster 1. } & 1 & 13 & 16 & 18 & 21 & 23 & 24 & 25 & 28 & 29 & 30 & \\ \text { Cluster 2. } & 5 & 7 & 12 & 14 & 15 & 17 & 20 & & & & & \\ \text { Cluster 3. } & 2 & 3 & 4 & 6 & 8 & 9 & 10 & 11 & 19 & 22 & 26 & 27\end{array}$

Cluster 4.

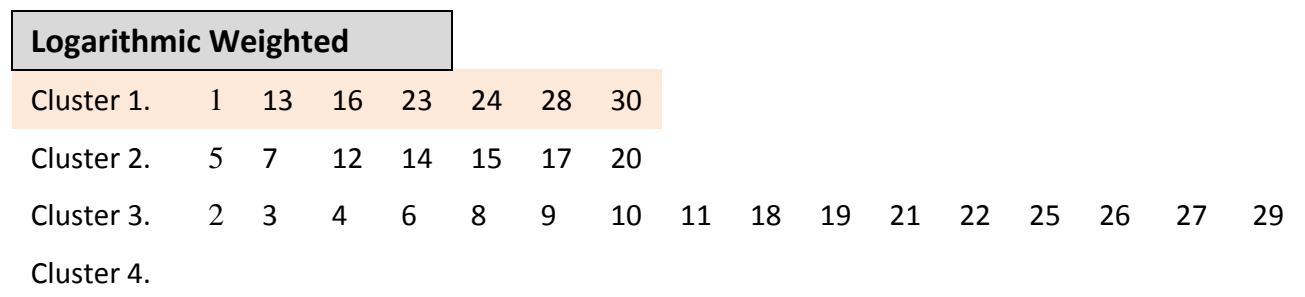

Table 6. Dominant Portfolios' and Excess Returns

\begin{tabular}{|lc|c|}
\hline Dominant Portfolio & \multicolumn{1}{c|}{ Return } & Excess Return \\
\hline Equally Weighted & $2.12 \%$ & $2.82 \%$ \\
Simple Weighted & $1.97 \%$ & $2.67 \%$ \\
Logarithmic & $0.75 \%$ & $1.45 \%$ \\
Weighted & $2.34 \%$ & $3.05 \%$ \\
Mutual Assets & $-0.70 \%$ & \\
\hline DIIA & \multicolumn{2}{|}{} \\
\hline
\end{tabular}

DJIA performs better than BIST-30 in backtesting period, however it still has a negative return. Results of both indexes correspond with each other, which means that equally weighted portfolios and mutual assets perform better than other methods. Equally weighted portfolio is the best among three different weighting methods. The portfolio, which consists of all methods' mutual stocks has also very similar return levels with equally weighted portfolio. 


\section{CONCLUSION}

In this paper, Second-order Stochastic Dominance portfolios from BIST-30 and DJIA components have been analysed with different weighting methods. First, exclusively dominant stocks are found to construct dominant portfolios. The stocks dominance revealed using different weighting tactics. Equally weighted tactic takes the historical returns with equal significance. Simple and Logarithmic weighting assign more significance on recent returns. DJIA's components did not take place in $4^{\text {th }}$ cluster, which means all stock are whether dominator or dominated by.

Next result shows that there is difference between various weighting methods. The highest excess return belongs to Equally weighted method. However, mutual stocks portfolio seems to have better performance. BIST-30's Simple-Weighted dominant portfolio performed with negative excess return which might be a sign of an inefficient market in Turkey. In the future, in light of these findings, stocks that make up these portfolios can be analysed with different time frequencies and different periods i.e. before financial crisis and post-crisis. One might study appropriate sample of indices to draw strong trend and relation between developed vs. developing markets and efficient vs. inefficient markets, as well.

\section{REFERENCES}

Best, R. J., Best, R. W., \& Yoder, J. (2000). Value Stocks and Market Efficiency. Journal of Economics and Finance, 24(1), 28-35.

Castellano, R., \& Cerqueti, R. (2013). Roots and effects of financial misperception in a stochastic dominance framework. Quality \& Quantity, 47(6), 3371-3389.

Copeland, T. E., Weston, J. F., \& Shastri, K. (1998). Financial Theory and Corporate Policy. Prentice Hall.

Dentcheva, D., \& Ruszczynski, A. (2003). Optimization with stochastic dominance constraints. SIAM Journal on Optimization, 14(2), 548-566.

Dentcheva, D., \& Ruszczynski, A. (2006). Inverse stochastic dominance constraints and rank dependent expected utility theory. Mathematical Programming, 108(2-3), 297-311.

Fong, W. M. (2009). Speculative trading and stock returns: A stochastic dominance analysis of the Chinese A-share market, . Journal of International Financial Markets, Institutions \& Money, 19, 712-727.

Guran, C. B., \& Tas, O. G. (2013). Second Order Stochastic Dominance Efficiency Test of a Portfolio. IISRO Conference. Dubai.

Hadar, J., \& Russell, W. R. (1969). Rules for Ordering Uncertain Prospects. American Economic Review, 59(1), 24-34.

Hanoch, G., \& Levy, H. (1969). The Efficiency Analysis of Choices Involving Risk. The Review of Economic Studies, 36(3), 335-346. 
Isiker, M., Tas, O., Tokmakcioglu, K., \& Ugurlu, U. (2014). Comparison of Ethical and Conventional Portfolios with Second-Order Stochastic Dominance Efficiency Test . International Interdisciplinary Business- Economics Advancement Conference (IIBA), (pp. 276-287). Istanbul.

Kopa, M., \& Chovanec, P. (2008). A second-order stochastic dominance portfolio efficiency measure. Kybernetika, 44(2), 243-258.

Kroll, Y., \& Levy, H. (1980). Stochastic dominance: a review and some new evidence. Research in Finance, II, 163-227.

Levy, H. (1992). Stochastic dominance and expected utility: survey and analysis. Management Science, 38(4), 555-593.

Levy, H. (1998). Stochastic Dominance: Investment Decision Making Under Uncertainty. New York: Springer Science \& Business Media.

Markowitz, H. (1952). Portfolio Selection. The Journal of Finance, 7(1), 77-91.

Markowitz, H. (1959). Portfolio Selection. New York: John Wiley \& Sons.

Marshall, A. W., Olkin, I., \& Arnold, B. C. (2011). Inequalities: Theory of Majorization and Its Applications. Spring series in statistics .

Ogryczak, W., \& Ruszczyn, A. (2002). Dual stochastic dominance and related mean-risk models. SIAM Journal of Optimization, 13(1), 60-78.

Sisson, R. L. (1965). Decision and Value Theory. Management Science, 12(4), C90-C93.

Tas, O., \& Güran, C. B. (2015). Making Second Order Stochastic Dominance inefficient Mean Variance Portfolio efficient. Iktisat Isletme ve Finans, 30(348), 69-94.

Tas, O., \& Ugurlu, U. (2015). Selection of Turkish Mutual Funds by Second-Order Stochastic Dominance Efficiency Test and Comparison With Conventional Portfolio Performance Measures. Conference of the International Journal of Arts\&Sciences, (pp. 163-172).

Tas, O., Guran, C. B., \& Ugurlu, U. (2014). Second Order Stochastic Dominance Portfolio Efficiency by Changing Data Frequency: An Application in Ten Different Country Indexes. Istanbul: 13th EBES CONFERENCE.

Whitmore, A. G. (1970). Third degree stochastic dominance. The American Economic Review, 60(3), 457-459. 